\title{
Genetic unit averages of pseudo-normalized pore throat radius for improved permeability predictions (Niger Delta as case study)
}

\author{
Haruna M. Onuh ${ }^{1}$ - O. Akeem Arinkoola ${ }^{1}$ O. Ogbe David ${ }^{1,2}$
}

Received: 18 September 2014 / Accepted: 22 March 2015/Published online: 4 April 2015

(C) The Author(s) 2015. This article is published with open access at Springerlink.com

\begin{abstract}
Recent studies in permeability modeling demonstrate a relationship between measured permeability and normalized pore throat radius $\overline{R_{\text {tot }}}$ that can be used as a predictor over six (6) orders of magnitude in permeability for the clastic reservoirs using Niger Delta dataset. The practical significance of this relationship indicates that the response variable (core permeability) is strictly valid within the confidence interval: $0.005 \leq \overline{R_{\mathrm{tot}}}(\mu \mathrm{m}) \leq 10$. The proposed model was validated extensively exhibiting an excellent correlation coefficient and statistical significance as depicted by their $p$ and $t$ tests. A major input parameter for the proposed $\overline{R_{\text {tot }}}$ permeability model is the pore throat radius at any given pressure step $\left(R_{p i}\right)$. This is an intrinsic component of capillary pressures obtained from mercury injection capillary pressures (MICP) test. The proposed model is hampered due to unavailability of MICP dataset for all wells drilled to generate the $R_{p i}$ parameter. This paper seeks to develop genetic unit averages of pseudo-normalized pore throat radius as input parameter to the $\overline{R_{\mathrm{tot}}}$ proposed model for improved permeability modeling. We also present an upscaling from core plug scale to well $\log$ scale-pseudo normalized pore throat radius for application in uncored well intervals for various depositional environments within the study area. The statistical significance of the coefficient of the proposed model depicts the sample statistic to be too unlikely to have occurred by chance, with their $p$ values strictly below the $\alpha$
\end{abstract}

Haruna M. Onuh

onuhharuna@yahoo.com

1 Petroleum Engineering Department, African University of Science and Technology, Km 10, Airport Road, Abuja, Nigeria

2 FlowGrids Limited, Port Harcourt, Nigeria level of 0.05 . The proposed model validation indicates an excellent adjusted correlation coefficient and lower errors based on analysis of variance (ANOVA) using approximately 1000 routine core and well log dataset from the four distinct environments of deposition.

Keywords Permeability modeling - Pseudo-normalized pore throat radius - Flow zone indicators (FZI's) · Niger Delta $\cdot$ Genetic unit averages $\cdot$ Statistical analysis

\section{Introduction}

Permeability and initial saturation are two of the key reservoir parameters to be defined in subsurface reservoir models. Detailed knowledge of these petrophysical parameters is essential in order to arrive at a realistic realization which best describes both the static and dynamic features of the reservoir. Inaccurate predictions of such petrophysical properties can result in significant cost due to inefficient completion and workover processes.

The sedimentary architecture of the Tertiary Niger Delta silici-clastic (Akata-Agbada) petroleum system is usually overprinted by late diagenesis resulting in intrinsic complexities which poses major problems to explorationist and petroleum engineers in modeling these systems. Although the average permeabilities of the various genetic reservoir units is relatively high, the low permeabilities of the component shale strata usually results in low sweep efficiencies and may form effective flow baffles. These clay breaks are expected to have a relatively low correlatability (Weber 1971), although they may extend up to $1000 \mathrm{~m}$ in length perpendicular to channel axis (Oomkens 1974). The variation in clay groups as a function of depth within various depobelts, suggest that the diagenetic overprint 
affecting the clastic rocks of the Niger Delta are both of environmental and sedimentary origin.

Hulea et al. (2011); proposed a novel normalized pore throat based permeability predictor (Eq. 1, 2)-for multimodal carbonate systems, which describes the relationship between permeability and normalized pore throat radius that can be used as a predictor over six (6) orders of magnitude in permeability, using mercury injection capillary pressures (MICP). The model incorporates characteristic capillary pressure behaviour using the Brooks-Corey model. The single constant " $A$ " characterizes the normalized pore throat radius for the carbonate system analyzed, with the coefficients: $A=1.55$ and $B=2.35$.

$\log _{10} K=A \log _{10} \overline{R_{\text {tot }}}+B$

where the normalized pore throat radius $\left(\overline{R_{\mathrm{tot}}}\right)$ is given by:

$\overline{R_{\mathrm{tot}}}=\phi_{i} \sum_{i} S_{\mathrm{wi}} R_{p i}=\varphi_{i} 10^{\sum_{i} \Delta s_{\mathrm{wi}} \log _{10} R_{p i}}$

and $\phi_{i}(\mathrm{v} / \mathrm{v})=$ contribution of the total porosity accessible at the $i$-th pressure step;

$S_{\mathrm{w} i}(\mathrm{v} / \mathrm{v})$ is incremental pore volume at the $i$-th pressure step;

$R_{p i}(\mu \mathrm{m})$ is pore throat radius at the $i$ th pressure step.

Haruna et al. (2013) validated the applicability of the proposed model for the clastic system, incorporating the Brooks-Corey and Lambda models for all the genetic reservoir units examined, for all pore throat size distribution using the Niger Delta datasets. The single constant " $A$ " also characterizes the normalized pore throat radius for the clastic system, but with varying coefficients: $A=1.913$ and $B=2.342$. The coefficient characterizing the normalized pore throat radius was validated to be statistically significant using an $\alpha$-level of 0.05 . The $P$ values were strictly below the $\alpha$-levels, and hence the sample statistic of the proposed model proves to be too unlikely to have occurred by chance.

A major input parameter for the proposed permeability model is the pore throat radius at the $i$-th pressure step $\left(R_{p i)}\right.$. This is an intrinsic component of capillary pressures obtained from MICP special core analysis dataset. The model is hampered due to unavailability of core dataset for all wells drilled to generate the $R_{p i}$ component.

This paper seeks to develop genetic unit averages of pseudo-normalized pore throat radius as input parameter to the proposed model for improved permeability modeling. We present an upscaling of the model from core to well log scale; for application in uncored well intervals for various depositional environments within the study area. The proposed $\overline{R_{\mathrm{tot}}}$ model has been validated using approximately 1000 corrected routine core analysis and corresponding well logs dataset at same formation depth interval.

\section{Sample selection and genetic reservoir units characterization}

The dataset for this work stems from four (4) distinct geological environments of deposition: the Continental/ Fluvial, Coastal/Distributary, Tidal/Estuarine and Turbiditic/Deep water environments; within the deltaic deposits of the Cenozoic Niger Delta; ranging in age from Middle to Late Miocene. The wide range in dataset is aimed at creating a representative database to honour the depositional fabric and diagenetic overprint of the study area.

Figures 1, 2 and 3 depicts the data obtained from the various depositional environment employed for this work. These include well logs: caliper, gamma ray, bulk density, neutron, resistivities and NMR; detailed geologic core

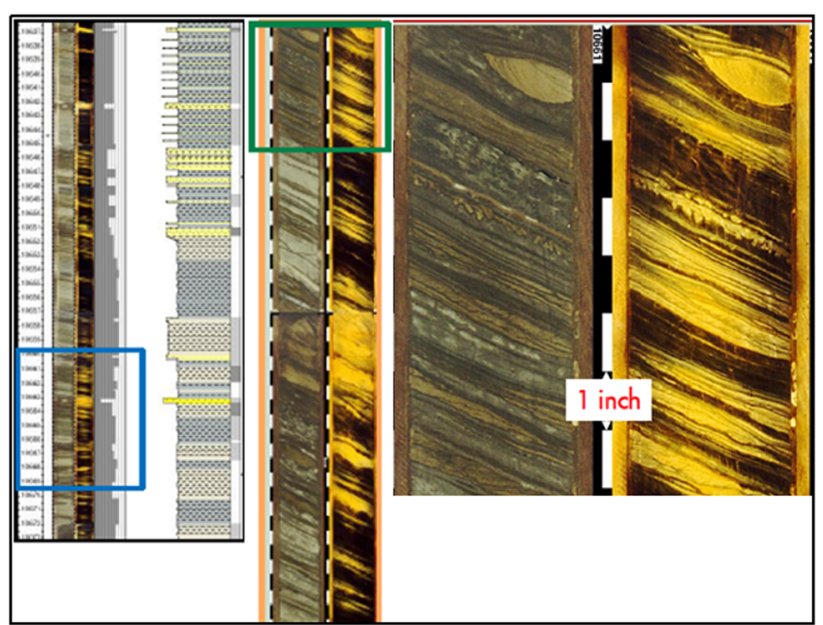

Fig. 1 Core interpretation; visible and ultra-violet image of the interchannel thin beds-deep water

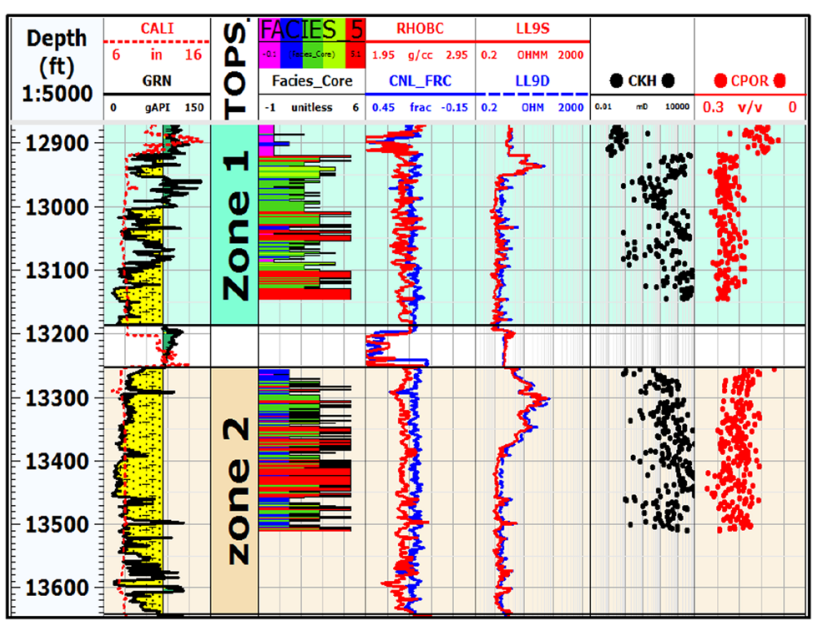

Fig. 2 Petrophysical data $\log (\mathrm{PDL})$ for field W-Continental environment indicating multi cored intervals 


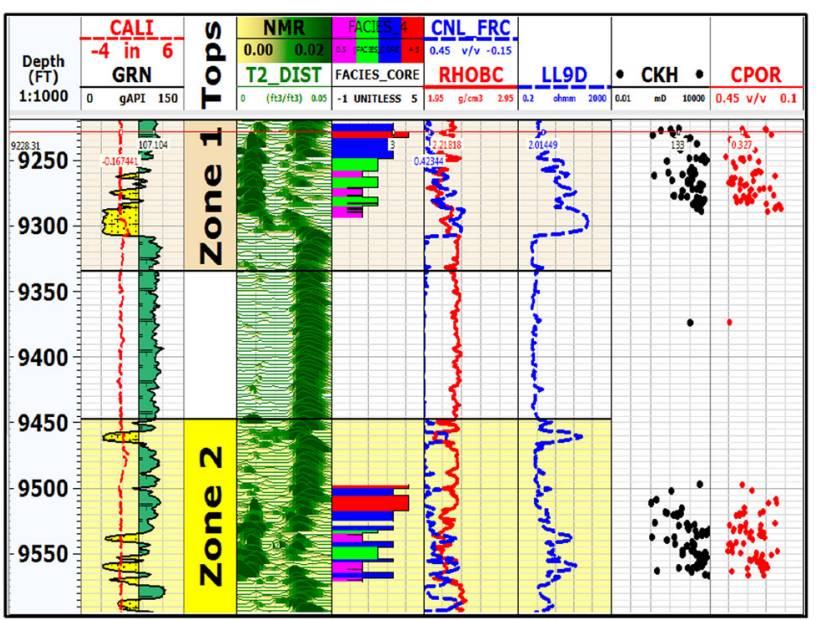

Fig. 3 Petrophysical data log (PDL) for field X-turbiditic environment indicating multi cored intervals

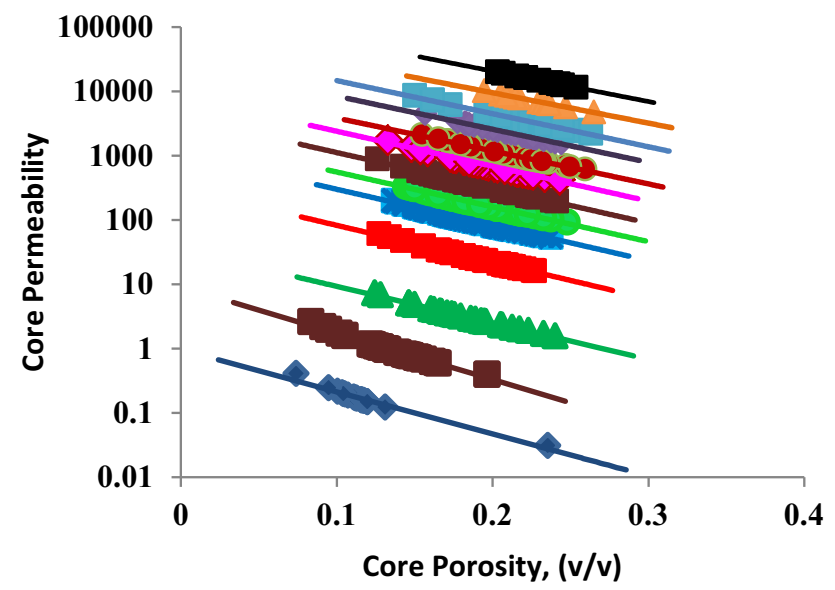

Fig. 4 Core permeability versus porosity for field W-continental environment (Genetic Unit Averages of $R_{\text {tot }}$ )

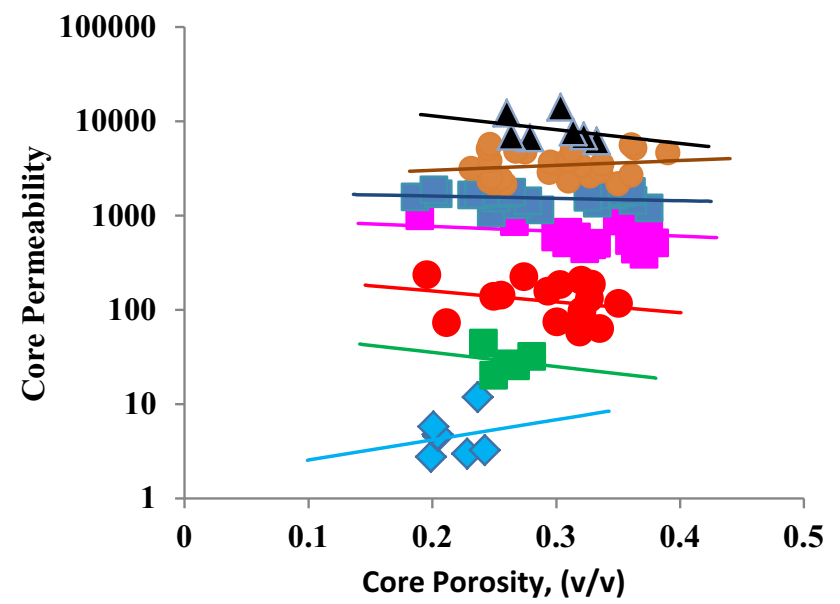

Fig. 5 Core permeability versus porosity for Field X-turbiditic environment (genetic unit averages of $R_{\mathrm{tot}}$ )
Table $1 R_{\text {tot }}$ for the Continental/fluvial depositional environment of the study area

\begin{tabular}{llll}
\hline Genetic reservoir units & $\begin{array}{l}\text { Minimum } \\
R_{\text {tot }}(\mu)\end{array}$ & $\begin{array}{l}\text { Mean } \\
R_{\text {tot }}(\mu)\end{array}$ & $\begin{array}{l}\text { Maximum } \\
R_{\text {tot }}(\mu)\end{array}$ \\
\hline Fluvial channel lag & 8.34 & 9.00 & 9.61 \\
Fluvial channel sandstone & 5.32 & 6.00 & 7.10 \\
Crevasse splay sandstone & 3.70 & 4.00 & 4.40 \\
Point bar sandstone & 2.78 & 3.00 & 3.42 \\
Coastal plain sandstone & 1.80 & 2.00 & 2.43 \\
Fluvial channel heterolithic & 1.37 & 1.50 & 1.64 \\
Bioturbated channel heterolithic & 0.84 & 1.00 & 1.18 \\
Stratified channel heterolithic & 0.44 & 0.70 & 0.77 \\
Point bar heterolithic & 0.18 & 0.25 & 0.37 \\
Coastal plain heterolithic & 0.06 & 0.08 & 0.10 \\
Coastal plain shales & 0.02 & 0.03 & 0.04 \\
Mud shale & 0.008 & 0.01 & - \\
\hline
\end{tabular}

description, stress corrected porosities and air permeabilities were available from routine core analysis.

The approach to genetic reservoir units characterization and sedimentologic analysis published by Shell Petroleum Development Co. (SPDC)-Geologic integration team documentation, 2009 was adopted for this study. The lithofacies subdivision provides the link which ensures that the petrophysical properties measured from core is properly incorporated into the volume cells (voxels) used in reservoir modeling. The representativeness of each genetic unit classification for the study was analyzed by carefully ensuring that the sample covers the full range of petrophysical characteristics (reservoir quality); and bears approximately same flow units (Figs. 4,5 ).

\section{Data analysis, results, and discussions}

The statistical analysis and practical significance of the $\overline{R_{\text {tot }}}$ based model for the clastic system indicates a confidence interval: $0.005 \leq \overline{R_{\mathrm{tot}}}(\mu \mathrm{m}) \leq 10$, for limit of predictions (Haruna et al. 2013, 2014). Based on the above premise, two approaches were considered:

1. Analysis of reservoir quality using core permeability versus porosity cross plots for all genetic units in each of the four distinct environment of deposition to demonstrate the ranges of pseudo-normalized pore throat radius. Only datasets measured at 400 psig were used to analyze for cross-plot relationships. Figures 4 and 5 depicts that the various genetic reservoir units within the depositional environment posses characteristic $\overline{R_{\text {tot }}}$. This emphasizes possible hydraulically connected flow units. Tables 1, 2, 3 and 4 express 
Table $2 R_{\text {tot }}$ for turbiditic/deepwater depositional environment of the study area

\begin{tabular}{llll}
\hline Genetic reservoir units & $\begin{array}{l}\text { Minimum } \\
R_{\text {tot }} \\
\text { (microns) }\end{array}$ & $\begin{array}{l}\text { Mean } \\
R_{\text {tot }} \\
\text { (microns) }\end{array}$ & $\begin{array}{l}\text { Maximum } \\
R_{\text {tot }} \\
\text { (microns) }\end{array}$ \\
\hline Channel lag & 8.23 & 9.00 & 9.67 \\
Channel storey axis & 5.40 & 6.00 & 7.30 \\
$\begin{array}{l}\text { Channel storey margin } \\
\text { Inter-channel thin beds }\end{array}$ & 3.60 & 4.00 & 4.90 \\
$\quad$ (ICTB) & 1.80 & 3.00 & 3.35 \\
$\begin{array}{l}\text { Mud-rich thin beds } \\
\quad \text { MRTB) }\end{array}$ & 0.63 & 0.70 & 0.84 \\
$\begin{array}{l}\text { Levees/overbank } \\
\text { Marine mudstone }\end{array}$ & 0.31 & 0.40 & 0.52 \\
\hline
\end{tabular}

Table $3 R_{\text {tot }}$ for coastal/distributary depositional environment of the study area

\begin{tabular}{|c|c|c|c|}
\hline Genetic reservoir units & $\begin{array}{l}\text { Minimum } \\
R_{\text {tot }}(\text { microns })\end{array}$ & $\begin{array}{l}\text { Mean } \\
R_{\text {tot }}(\text { microns })\end{array}$ & $\begin{array}{l}\text { Maximum } \\
R_{\mathrm{tot}}(\text { microns })\end{array}$ \\
\hline Foreshore & 8.34 & 7.00 & 9.61 \\
\hline $\begin{array}{l}\text { Distributary channel } \\
\text { sandstone }\end{array}$ & 5.32 & 6.00 & 7.10 \\
\hline $\begin{array}{l}\text { Upper shoreface } \\
\text { sandstone }\end{array}$ & 3.70 & 5.00 & 4.40 \\
\hline Mouth bar & 2.78 & 4.00 & 3.42 \\
\hline Transgressive lag & 1.80 & 3.00 & 2.43 \\
\hline Transgressive shoreface & 1.37 & 2.00 & 1.64 \\
\hline Middle shoreface & 0.84 & 1.50 & 1.18 \\
\hline $\begin{array}{l}\text { Bioturbated channel } \\
\text { heterolithic }\end{array}$ & 0.62 & 0.60 & 0.77 \\
\hline $\begin{array}{l}\text { Stratified channel } \\
\text { heterolithic }\end{array}$ & 0.18 & 0.20 & 0.30 \\
\hline $\begin{array}{l}\text { Proximal lower } \\
\text { shoreface heterolithic }\end{array}$ & 0.06 & 0.10 & 0.19 \\
\hline $\begin{array}{l}\text { Distal lower shoreface } \\
\text { heterolithic }\end{array}$ & 0.02 & 0.04 & 0.06 \\
\hline Marine shale & 0.008 & 0.005 & 0.010 \\
\hline
\end{tabular}

the various ranges of pseudo $\overline{R_{\text {tot }}}$ for the four distinct depositional environments within the deltaic Niger Delta clastic system.

2. Multiple non-linear regressions of genetic unit averages of pseudo $\overline{R_{\mathrm{tot}}}$ for the distinct depositional environments demonstrates that comparing core derived permeability and $\overline{R_{\text {tot }}}$ predicted permeability, under-estimates the in situ measured permeabilities (Fig. 6). This was applicable to all the depositional environment. This is expected since the earlier works were based on dataset at core plug scale (Eqs. 1, 2). In essence, there is need for model upscaling to account
Table $4 R_{\text {tot }}$ for Tidal/estuarine depositional environment of the study area

\begin{tabular}{llll}
\hline Genetic reservoir units & $\begin{array}{l}\text { Minimum } \\
R_{\text {tot }}(\text { microns })\end{array}$ & $\begin{array}{l}\text { Mean } \\
R_{\text {tot }}(\text { microns })\end{array}$ & $\begin{array}{l}\text { Maximum } \\
R_{\text {tot }}(\text { microns })\end{array}$ \\
\hline Estuarine channel lag & 8.00 & 9.1 & 9.7 \\
$\begin{array}{l}\text { Estuarine channel } \\
\quad \text { sandstone }\end{array}$ & 5.80 & 6.00 & 8.20 \\
$\quad$ Tidal channel bar & 3.62 & 4.00 & 5.23 \\
$\quad \begin{array}{l}\text { Tidal channel sandstone } \\
\text { Crevasse channel }\end{array}$ & 2.56 & 3.00 & 3.60 \\
$\quad 1.84$ & 2.00 & 2.26 \\
$\quad$ sandstone & & & \\
$\quad$ Estuarine channel & 0.80 & 1.00 & 1.37 \\
$\quad$ heterolithic & & & \\
$\quad \begin{array}{l}\text { Stratified channel } \\
\quad \text { heterolithic }\end{array}$ & 0.28 & 0.50 & 0.73 \\
$\quad \begin{array}{l}\text { Transgressive sand } \\
\text { Tidal flat }\end{array}$ & 0.04 & 0.30 & 0.08 \\
$\quad$ Marine shale & 0.01 & 0.05 & 0.04 \\
\hline
\end{tabular}

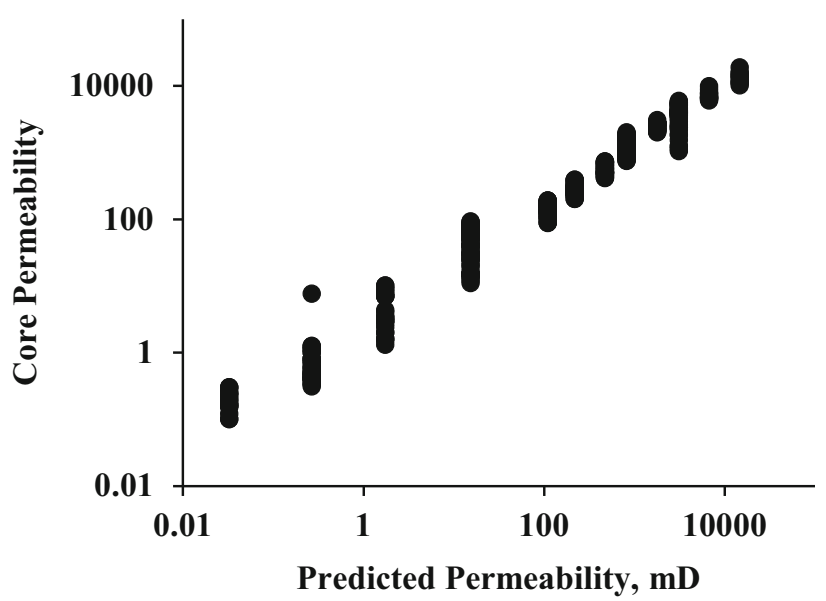

Fig. 6 Plot of core permeability versus predicted permeability for field W-continental/fluvial environment

for the discrepancies between the measured and predicted values.

Traditionally, the Kozeny-Carman equation relates permeability to porosity and grain size:

$K_{\text {absolute }} \approx d^{2} \varphi^{3}$

This form is frequently employed to mimic permeability versus porosity relationships, such as in Finney pack (Finney 1970). The grain size " $d$ " is typically kept constant during such calculations. Such approach introduces at least two errors: (a) the Kozeny-Carman equation is based on an idealized solid medium with pipe conduits, rather than a realistic granular medium and (b) even if a grain size is used, it is obvious that it varies with varying porosity. 
Bearing this argument in mind, we explore how permeability can be predicted consistently within the KozenyCarman formalism, by varying the radii of the conduits, their number, and type for effective modeling of the subsurface reservoir. This requires additional assumptions, specifically, regarding tortuosity evolution during porosity reduction.

In the end, we arrive at a normalization of the using a gin to pore volume $\left(\varphi_{z}\right)$ ratio:

$\log _{10} K=A \log _{10} \overline{R_{\text {tot }}} \varphi_{Z}+B$

The single constant " $A$ " characterizes the normalized pore throat radius for the clastic system analyzed, with the coefficients: $A=1.913$ and $B=2.342$.

The parameter, $\varphi_{z}$ termed the normalized grain to pore volume ratio is given by:

$\varphi_{z}=0.3\left(\frac{1-\varphi}{\varphi}\right)$

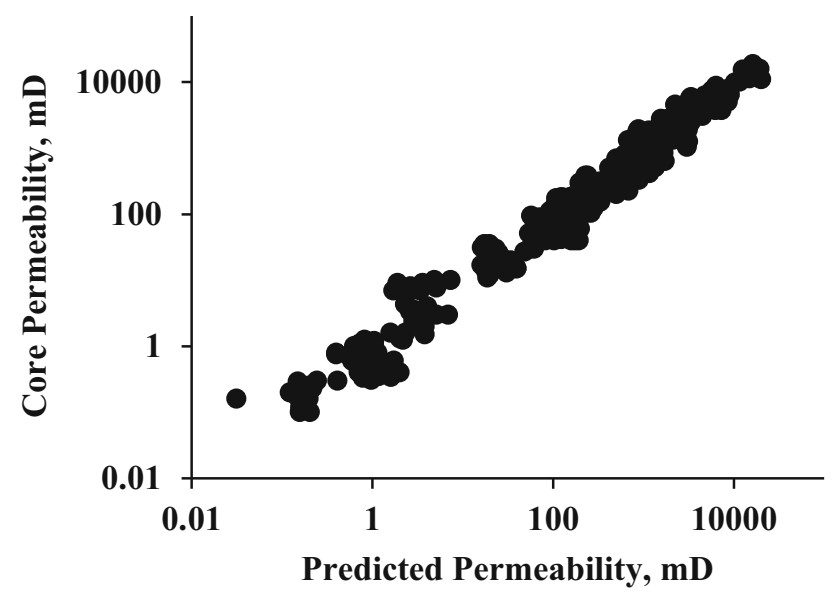

Fig. 7 Plot of core permeability versus $R_{\text {tot }}$ predicted permeability for Field W-continental/fluvial environment

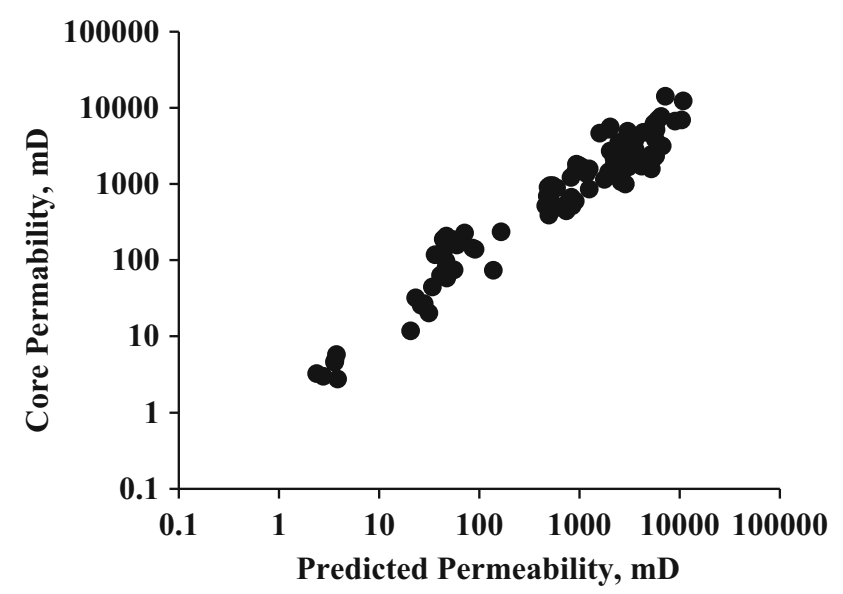

Fig. 8 Plot of core permeability versus $R_{\text {tot }}$ predicted permeability for field X-turbiditic/DW environment
This accounts for the specific surface area of the porous medium (specific pore volume) or the total area exposed within the pore space per unit of grain volume. An $\alpha$-level of 0.05 was chosen to verify the statistical significance of the coefficients in the proposed relationship between the response and predictor variable $\left(\overline{R_{\text {tot }}} \varphi_{Z}\right)$. The $P$-values were strictly below the $\alpha$-levels, and hence the sample statistic of the proposed model proves to be too unlikely to have occurred by chance.

\section{Proposed model validation for the various depositional environment}

The proposed genetic unit averages of pseudo-model (Eq. 4) was validated using dataset from the four (4) fields within various depositional environment of the Niger Delta. In each case, the core permeability was measured using a nitrogen gas under a sleeve pressure of $400 \mathrm{psig}$ permeameter and was corrected for the Klinkenberg effects.

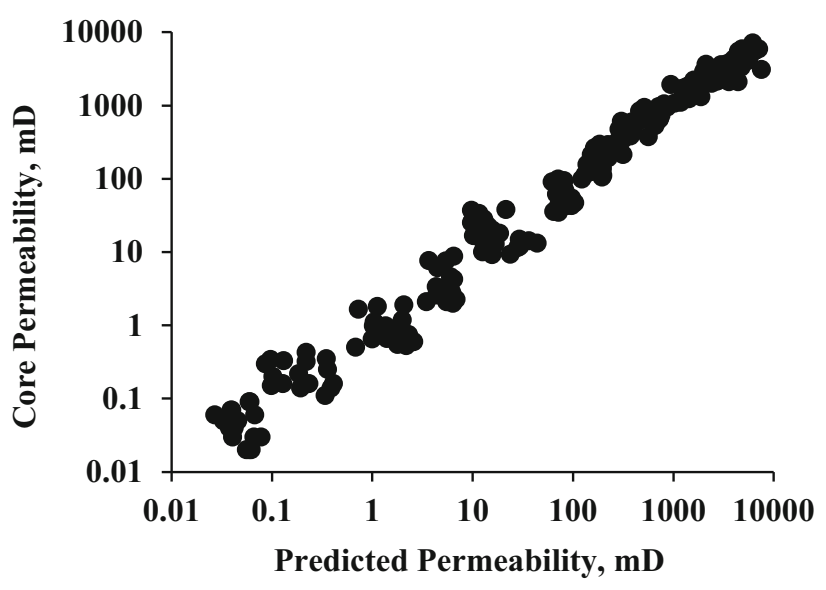

Fig. 9 Plot of core permeability versus $R_{\text {tot }}$ predicted permeability for field Y-coastal/distributary environment

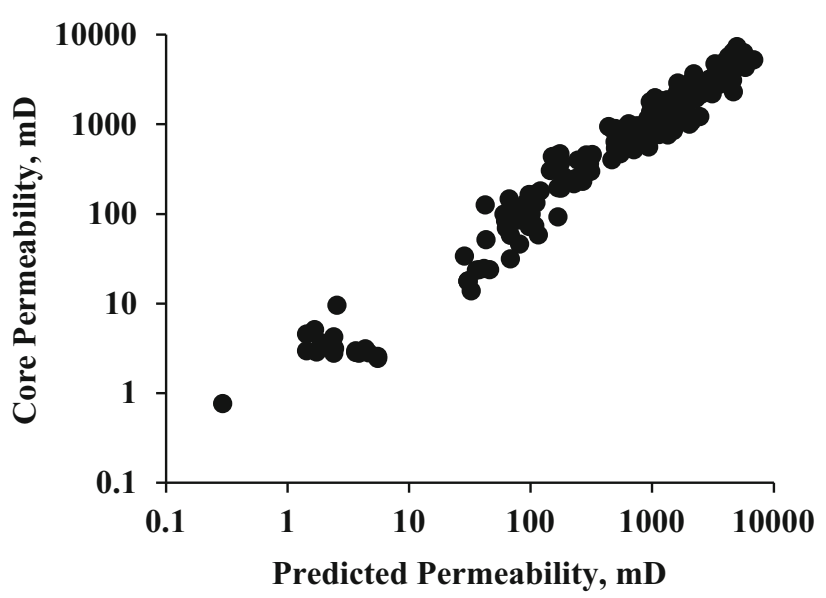

Fig. 10 Plot of core permeability versus $R_{\text {tot }}$ predicted permeability for field Z- tidal/estuarine environment 


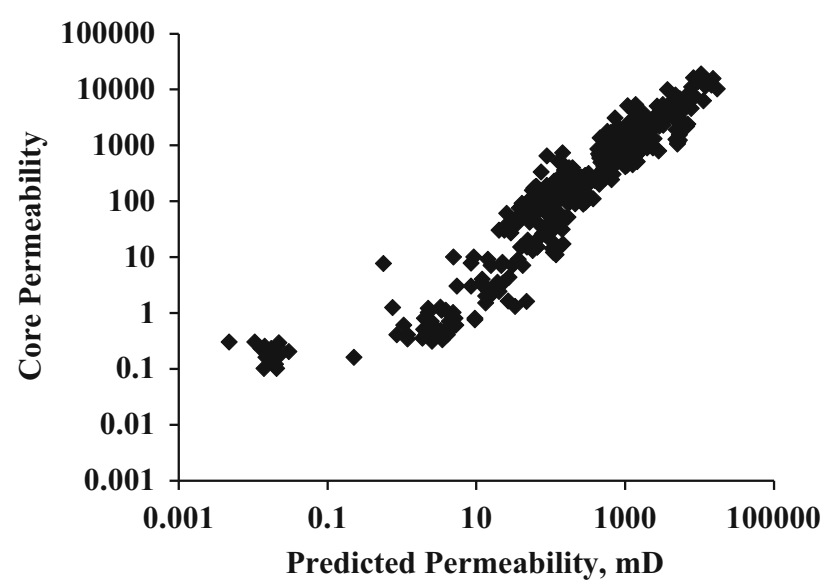

Fig. 11 Plot of core permeability versus FZI predicted permeability for field $\mathrm{W}$-continental/fluvial environment

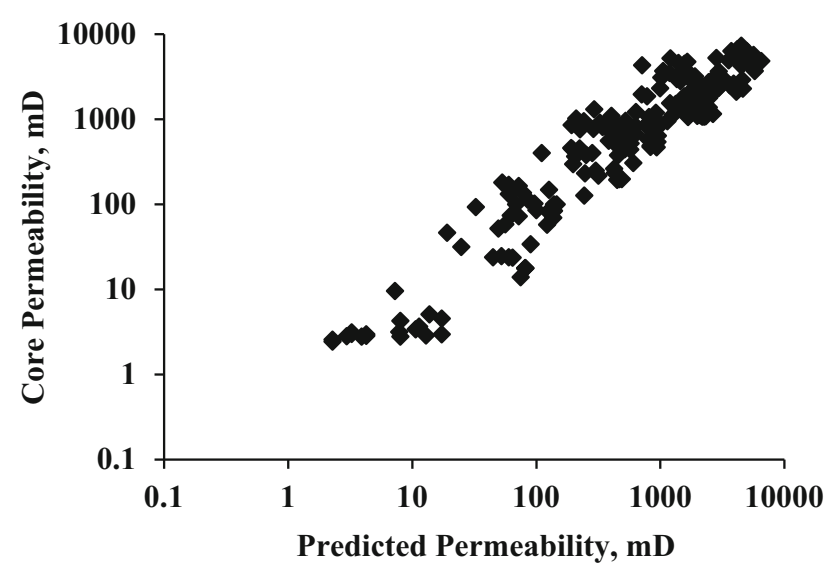

Fig. 12 Plot of core permeability versus FZI predicted permeability for field Y-tidal/estuarine environment

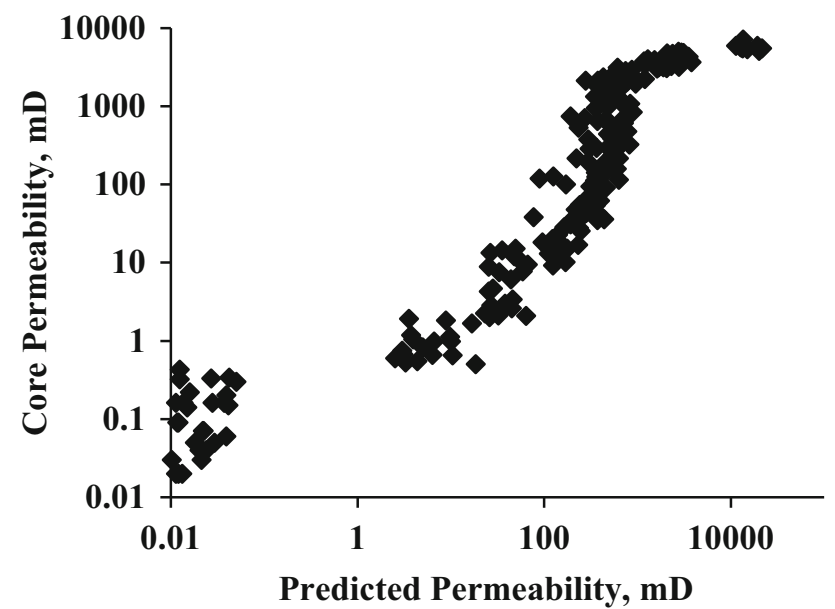

Fig. 13 Plot of core permeability versus FZI predicted permeability for field Z-coastal/distributary environment

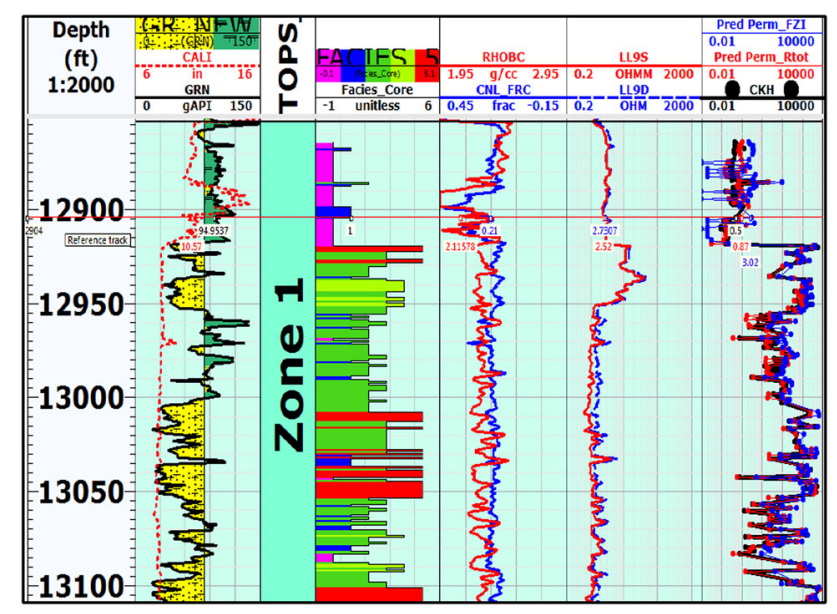

Fig. 14 Petrophysical data $\log$ (PDL) for field W-continental environment indicating multi cored intervals

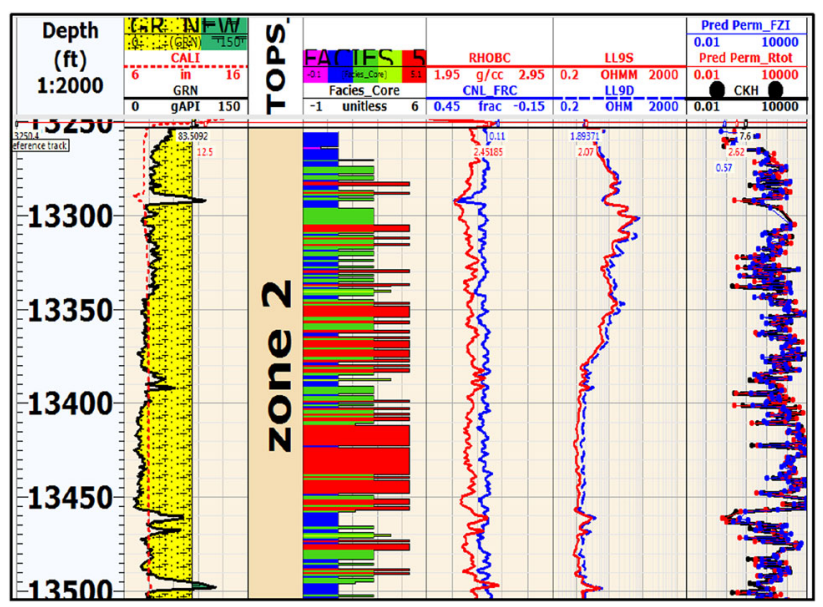

Fig. 15 Petrophysical data $\log (\mathrm{PDL})$ for field W-continental environment indicating multi cored intervals

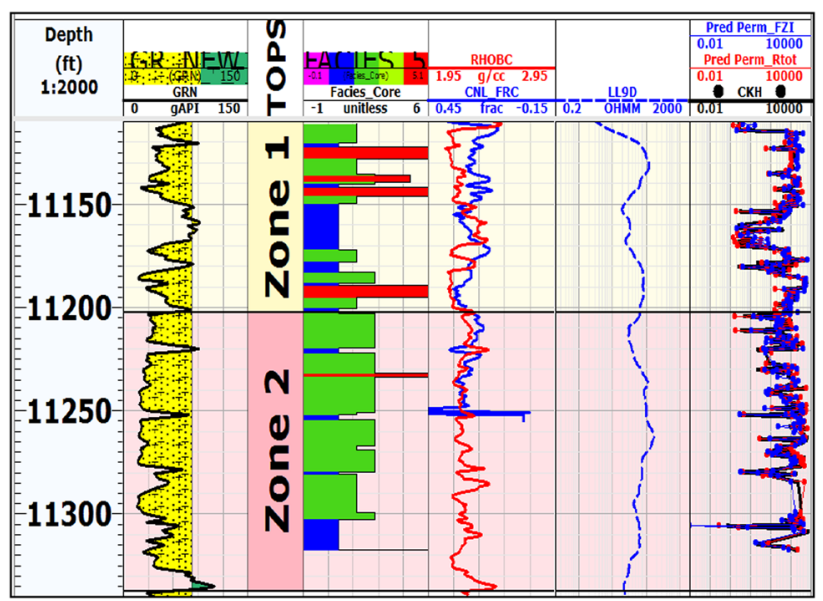

Fig. 16 Petrophysical data log (PDL) for field Y-continental environment indicating multi cored intervals 
Table 5 Statistical error analysis of permeability models in various depositional environment

\begin{tabular}{|c|c|c|c|}
\hline Statistical parameters & Perm_measured & Perm_ $R_{\text {tot }}$ & Perm_FZI \\
\hline \multicolumn{4}{|c|}{ A. Continental/fluvial depositional environment of the study area } \\
\hline Number of samples & 445 & 445 & 445 \\
\hline Maximum & 18,755 & 19,167 & 17,426 \\
\hline Minimum & 0.10 & 0.031 & 0.005 \\
\hline Mean & 1352 & 1354 & 1365 \\
\hline Standard deviation (SD) & 2501 & 2607 & 2402 \\
\hline Average deviation (AD) & & -2 & -13 \\
\hline Average absolute deviation (AAD) & & 331 & 517 \\
\hline Maximum error $\left(E_{\max }\right)$ & & 400 & 2889 \\
\hline Average absolute percentage relative error (AAPRE) & & 44 & 136 \\
\hline Correlation coefficient $\left(R^{2}\right)$ & & 0.968 & 0.885 \\
\hline Adjusted correlation coefficient $\left(R^{2}\right)$ & & 0.968 & 0.883 \\
\hline Pearson correlation & & 0.963 & 0.883 \\
\hline$T$ student distribution & & -0.071 & -0.235 \\
\hline Fisher $F$ test & & 0.920 & 1.085 \\
\hline$P$ value $(\alpha=0.05)$ & & 0.000 & 0.000 \\
\hline \multicolumn{4}{|l|}{ B. Tidal/estuarine depositional environment of the study area } \\
\hline Number of samples & 206 & 206 & 206 \\
\hline Maximum & 7310 & 6901 & 6554 \\
\hline Minimum & 0.76 & 0.294 & 0.008 \\
\hline Mean & 1387 & 1336 & 1246 \\
\hline Standard deviation (SD) & 1571 & 1523 & 1382 \\
\hline Average deviation (AD) & & 50 & 141 \\
\hline Average absolute deviation (AAD) & & 325 & 569 \\
\hline Maximum error $\left(E_{\max }\right)$ & & 137 & 489 \\
\hline Average absolute percentage relative error (AAPRE) & & 32 & 62 \\
\hline Correlation coefficient $\left(R^{2}\right)$ & & 0.964 & 0.874 \\
\hline Adjusted correlation coefficient $\left(R^{2}\right)$ & & 0.968 & 0.874 \\
\hline Pearson correlation & & 0.939 & 0.803 \\
\hline$T$ student distribution & & 1.337 & 2.140 \\
\hline Fisher $F$ test & & 1.064 & 1.292 \\
\hline$P$ value $(\alpha=0.05)$ & & 0.000 & 0.003 \\
\hline \multicolumn{4}{|c|}{ C. Coastal/distributary depositional environment of the study area } \\
\hline Number of samples & 256 & 256 & 256 \\
\hline Maximum & 7120 & 7554 & 12,326 \\
\hline Minimum & 0.02 & 0.027 & 0.005 \\
\hline Mean & 1235 & 1295 & 990 \\
\hline Standard deviation (SD) & 1714 & 1871 & 1977 \\
\hline Average deviation (AD) & & -60 & 245 \\
\hline Average absolute deviation (AAD) & & 229 & 684 \\
\hline Maximum error $\left(E_{\max }\right)$ & & 331 & 3597 \\
\hline Average absolute percentage relative error (AAPRE) & & 48 & 267 \\
\hline Correlation coefficient $\left(R^{2}\right)$ & & 0.979 & 0.849 \\
\hline Adjusted correlation coefficient $\left(R^{2}\right)$ & & 0.979 & 0.848 \\
\hline Pearson correlation & & 0.967 & 0.799 \\
\hline$T$ Student distribution & & -1.971 & 3.276 \\
\hline Fisher $F$ test & & 0.839 & 0.752 \\
\hline$P$ value $(\alpha=0.05)$ & & 0.000 & 0.000 \\
\hline
\end{tabular}


444 measured core permeabilities were obtained from two (2) separate reservoirs from Field "W"-continental/ Fluvial Environment (Fig. 2). A plot of the measured versus predicted permeabilities (Fig. 7) results in an excellent adjusted correlation coefficient $\left(R^{2}\right)$ of 0.97 and root mean square error (RMSE) of 0.01 .

Field " $\mathrm{X}$ " located within the Turbiditic/Deep water offshore depositional environment has 103 measured core dataset covering two (2) prolific canyon reservoirs (Fig. 3). A plot of the corrected core permeability versus predicted permeability gave an adjusted $R^{2}$ of 0.93 and RMSE value of 0.092 (Fig. 8).

205 routine core analysis datasets were also obtained from two (2) wells within the coastal/distributary depositional environment-Field "Y" at different depth intervals. Plot of the corrected core permeability versus predicted permeability gave an adjusted $R^{2}$ of 0.964 and RMSE value of 0.021 (Fig. 9).

Finally, the proposed model was applied to Field " $Z$ " with 255 core dataset obtained from two (2) wells within the tidal/estuarine environment. Figure 10 shows a plot of the measured versus predicted permeabilities, showing adjusted $R^{2}$ of 0.979 and RMSE of 0.010 .

\section{Statistical analysis of the proposed model}

A comparative evaluation of the proposed and existing permeability correlation based on Genetic Unit Averages of Flow zone indicators (FZIs) and Neural Networks for Niger Delta was performed to evaluate the competence and applicability of the proposed model.

Figures 11, 12 and 13 shows a plot of corrected air permeabilities versus FZI based permeability for various depositional systems applicable to this work. Track 7 of Figs. 14, 15 and 16 displays a depth plot of the proposed model and existing genetic units based FZI model indicating reasonable relationship within various depositional environment.

Table $5 \mathrm{a}-\mathrm{c}$ shows the summary of statistical analysis with respect to the corrected measured permeabilities at same reference depth. The lower standard errors and appreciable adjusted least squares correlation coefficient for all environments analyzed within the clastic reservoir system is indicative of a strong relationship between the predictor and response variables for the proposed model. It suffices to say that the sample statistic is statistically significant and therefore the test's null hypothesis is rejected.

\section{Conclusions}

A pseudo-normalized pore throat radius has been developed for various depositional environments within the clastic Niger Delta system based on genetic reservoir unit averages.
An attempt has also been made in upscaling the proposed model from core to log scale-for application in uncored well intervals for various depositional environments within the study area. The coefficients: $A=1.913$ and $B=2.342$ defines Eq. 1 which describes the relationship between permeability and pseudo-normalized pore throat radius that can be used as a predictor over six (6) orders of magnitude in permeability for all the genetic reservoir units examined, for all pore throat size distribution in the study area. Statistical analysis (Table 5) of the coefficient for each genetic reservoir units analyzed has proven that the sample statistic is statistically significant and therefore the test's null hypothesis is rejected based on an $\alpha$-value of 0.05 .

Subsurface reservoirs can be subdividing into distinct normalized pore throat radius with specified index, which describes the reservoir quality and flow zones.

The proposed model has been tested in four (4) distinct depositional environments within the Niger Delta Province, with approximately 1000 routine core analysis dataset and well logs of various genetic units. In all cases, the proposed model has outperformed other common prediction methods resulting in a lower maximum error as well as lower average absolute relative error making it more attractive than other correlations as observed in Table 5. The lower average absolute relative error of the proposed model is expected to greatly reduce the uncertainties associated with reservoir characterization and simulation for excellent sweep.

Acknowledgments The authors would like to thank the management of Shell Petroleum Development Company (SPDC) where the research was conducted, the Department of Petroleum Resources (DPR), and the Petroleum Technology Development Fund (PTDF), Nigeria, for their support and permission to publish this article. Special thanks and appreciation to the SPDC petrophysics and geosolution team who were involved in discussions that made this possible, and to Schlumberger for their Techlog petrophysical and statistical tool.

Open Access This article is distributed under the terms of the Creative Commons Attribution 4.0 International License (http:// creativecommons.org/licenses/by/4.0/), which permits unrestricted use, distribution, and reproduction in any medium, provided you give appropriate credit to the original author(s) and the source, provide a link to the Creative Commons license, and indicate if changes were made.

\section{References}

Finney J (1970) Random packing and the structure of simple liquids (The geometry of random close packing). Proc R Soc 319A:479

Hulea IN, Nicholls CA (2011) "Carbonate rock characterization and modeling-capillary pressure and permeability in multimodal rocks—a look beyond sample specific heterogeneity", AAPG bulletin. April 10-13 
Onuh Haruna, David Ogbe, Nwosu Chike (2013) Reservoir characterization for improved petrophysical properties predictability and validations: capillary pressures and permeability (Niger Delta Province as Case Study), SPE 165958, September

Oomkens E (1974) Lithofacies relations in the late quaternary Niger Delta complex. Sedimentology 21:195-222
Uguru CI, Onyeagoro UO, Lin J, Okkerman J, Sikiru IO, SPDC (2005) Permeability prediction using genetic unit averages of flow zone indicators (FZIs) and neural networks, SPE 98828, August

Weber KJ (1971) Sedimentological aspects of oil fields in the Niger Delta. Geol Mijnbouw 50:559-576 